Covered in: ERIH PLUS, HeinOnline, CEEOL, Index Copernicus, CrossRef, CrossCheck, J-GATE, Google Scholar, Ideas RePeC, Econpapers, Socionet, KVK, WorldCat.

2018, Volume 6, Issue 1, pages: 37-40 | doi: https://doi.org/10.18662/lumenlaw/05

\section{Protection of Personal Data}

\section{Ileana-Gabriela PINTILIUC1 \\ 1"Stefan cel Mare" University, Suceava, Romania, gabytza_pintiliuc19@yahoo.com}

\begin{abstract}
The protection of personal data implies the right of the individual to defend those characteristics that lead to his identification and the correlative liability of the state to take appropriate measures to ensure effective protection. The individuals' fundamental right to private and intimate life has to be protected and defended, so the protection of personal data implies a particularly important area. We have to make it clear that technology has evolved rapidly and new challenges for personal data protection have emerged, allowing both private companies and public authorities to use personal data at an unprecedented level in their work. Broadly speaking, personal data means information that can be directly or indirectly related to an identified or identifiable personal.
\end{abstract}

Keywords: personal data, protection, direction, people, respect, law, technology.

How to cite: Pintiliuc, I.-G. (2018). Protection of Personal Data. Logos Universality Mentality Education Novelty: Law, 6(1), 37-40. https://doi.org/10.18662/lumenlaw/05 


\section{Introduction}

Right from the beginning of our lives, we have personal data that grow with us. Our first data is our name and surname, and then they multiply and we can talk about home, e-mail, phone number, etc., all of which help to identify every person, either directly or indirectly. When we want to open a bank account, join a college, when we book an online ticket or when we want to make a payment through the bank card, we need to provide personal data.

\section{Introductory notions}

In order to better understand what personal data represents, Romanian Law no. 677/2001 (Romanian Law no. 677/2001) on the protection of individuals with regard to the processing of personal data and the free movement of such data, as subsequently amended and supplemented, defines personal data in art. 3 (a), as follows: "Any information relating to an identified or identifiable natural person; an identifiable person is one who can be identified, directly or indirectly, in particular by reference to an identification number or to one or more factors specific to his or her physical, physiological, psychological, economic, cultural or social identity."

Also, the same Romanian law that was mentioned above, at art. 3 (b), the processing of personal data is defined as follows: "Any operation or set of operations that is performed on personal data by automatic or nonautomatic means such as the collection, recording, organization, storage, adaptation or modification, extraction, consultation, use, disclosure to third parties by transmission, dissemination or in any other way, joining or combining, blocking, deleting or destroying."

According to the legal provisions in force, the Romanian Police, as an operator, has the obligation to respect the privacy and the security of the processing of personal data of each person. It also has the obligation to manage safely the specific databases created for the fulfillment of its legal duties and to ensure the registered persons, as the persons concerned, the specific rights stipulated in the Romanian Law no. 677/2001, as subsequently amended and supplemented.

The National Supervisory Authority for Personal Data Processing in Romania aims to protect the fundamental rights and freedoms of individuals, in particular the right to intimate, family and private life in connection with the processing of personal data and the free circulation of such data. (institution specific to the field) At present, the way personal data 
are collected and processed are constantly evolving, thus generating three personal data protection challenges.

According to the Romanian legislation in force, the data are not stored in a structured database in a first phase, but they are composed of non-structural electronic information (e-mails, photos or messages), thus the application of traditional protection laws of data to unstructured data is a real challenge. In the second phase, it is said that there has been an explosive increase in the volume of data, and most data have been made over the past two years, more than in the previous history. And thirdly, it is about the fact that national borders are no longer being respected, because the Internet allows information to circulate around the world easily and instantly.

\section{European legislative framework}

The issues outlined above were the main considerations for establishing a solid and coherent framework for personal data in the European Union, together with a more rigorous application of the rules. On May 4, 2016, two pieces of legislation were drawn up which make up the legislative package on data protection at EU level, namely: General Regulation (EU) 2016/679 and Directive (EU) 2016/680 on data protection in the specific activities of law enforcement authorities.

The regulation brings new guarantees on strengthening the right to privacy in the new digital age and its provisions have been in force since 25 May 2018 in all EU Member States. The provisions of Directive (EU) 2016/680 on the protection of personal data in specific activities carried out by law enforcement authorities have a two-year deadline for the Member States to transpose them into national law.

\section{Guaranteed rights}

According to the National Supervisory Authority for Personal Data Processing in Romania, we have the following novelty elements introduced by Regulation (EU) 2016/279: first of all it is directly applicable in all EU Member States, then it protects the rights of all persons within the EU and extends scope to data providers established outside the EU.

New rights are guaranteed as follows: the right to be forgotten, the portability of data, specific provisions on minors, proximity to the data subject, enhanced cooperation between supervisory authorities, and for data controllers we have the following: one stop shop, data operator responsibility, impact study, data transfer outside the EU, privacy by design 
\& privacy by default, DPO - data protection officer (Guidelines for the Application of the General Regulation on Data Protection to Operators).

\section{Conclusions}

Rapid technological developments and globalization have created new challenges for the protection of personal data, allowing both private companies and public authorities to use personal data at an unprecedented level in their activities.

Technology has also transformed the economy and social life and should further facilitate the free movement of personal data within the Union and the transfer to third countries and international organizations, while ensuring a high level of protection of these data.

\section{Bibliography}

Guidelines for the Application of the General Regulation on Data Protection to Operators, the National Supervisory Authority for Personal Data Processing

http://www.dataprotection.ro/?page=Regulamentul 679 din 2016 https:/ / ccj.ro/protectia-datelor-cu-caracter-personal-si-reforma-cadruluilegislativ-consilier-juridic-filip-gabriela-alexandra/

Romanian Law no. 677/2001 on the protection of individuals with regard to the processing of personal data and the free movement of such data

Testing, Evaluation and Regular Assessment of the Effectiveness of Technical and Organizational Measures, 23 February 2017, Romsym Data Conference, Adrian MUNTEANU Presentation 